\title{
Impact Investing in Asia: Just Getting Started
}

\author{
Ruth A. Shapiro
}

For most of the twentieth century, nonprofit organizations relied on a static funding model: foundations supplied grants to charities that delivered services otherwise not available for a variety of reasons, including budgetary constraints (for example, health care for the poor) or because of the innovative but still unproven nature of the work (for example, new models of helping at-risk youth).

Beginning in the early 1980s, nonprofit organizations evolved and diversified, taking on new characteristics throughout the 1990s that would change the way philanthropists and nonprofit organizations now think about and act on their work. Many of these changes result from an increased understanding and application of the tenets of social entrepreneurship.

In 1981, Bill Drayton introduced the concept of a social entrepreneur when he created Ashoka, now a global leader in incubating talent and ideas in the social sector. Drayton put forward the idea that a social entrepreneur is someone who takes the passion and rigor of an entrepreneur and applies it to a social problem. This was a new idea in two important ways. First, most philanthropy up until that point focused on the organization rather than on its leadership and talent. Second, it introduced the notion that nonprofits should still follow basic business tenets, including sound management, transparent accounting, and strategic planning.

\footnotetext{
R.A. Shapiro

CAPS, Hong Kong SAR, China
}

(C) The Author(s) 2018

R.A. Shapiro et al., Pragmatic Philanthropy, https://doi.org/10.1007/978-981-10-7119-5_8 
Since that time, these ideas have led to a host of changes and innovations that have changed the sector in important ways.

The first major change has been the blurring of the previously sacrosanct demarcation between profit and nonprofit. What started off as the adoption of corporate rigor has evolved into the implementation of numerous business tools, such as the use of profit as a motive or the notion that key performance indicators (KPIs) are applicable in nonprofit management as well. This has shaken out with organizations sitting at various points on the profit-nonprofit continuum, offering an array of options for funders.

One of the most powerful social investment trends to emerge from this new thinking is the creation of social enterprises on the organizational side and impact investing on the funding side. The term social enterprise is used often to refer to a host of initiatives and models. A social enterprise must perform the delicate balancing act of meeting its financial obligations while staying true to its social imperatives.

\section{IMPACT INVESTING AND AsIA}

On the funding side, charitable application of the profit motive is called "impact investing." The Global Impact Investing Network (GIIN) defines impact investments as "investments made into companies, organizations, and funds with the intention to generate social and environmental impact alongside financial returns." Once again, there is variation, but mostly in terms of expectations of what kinds of financial returns the investor is looking to receive. The Acumen Fund, a pioneer impact investment fund, uses the term patient capital to indicate a time lag before seeing returns for the companies in its portfolio, perhaps at below-market rates. In Asia, Acumen has invested \$31.9 million spread over 26 companies in India, and in Pakistan, \$15 million in 16 companies. Their funds promote affordable housing, solar power, and private education, among other things.

Private equity giant TPG's new social development fund, Rise, sits on the side of the return spectrum offering market returns for its investors. In addition to big names such as Bono and Jeff Skoll, Rise has attracted several pension and sovereign wealth funds. The New York Times reports that three such funds have invested nine-figure sums. In the same article, Rise managing partner Bill McGlashan says, "The reality is that no matter which side of the aisle you're on, and no matter where your framework is, if I can build a great business that's profitable and successful and, oh, by the way, here's the impact and the multiple of impact that's created through that business's successes, I think 
that's good for everybody." ${ }^{1}$ Rise targets businesses that are building infrastructure, telecom, energy, and for-profit education. ${ }^{2}$

Even the Ford Foundation has joined in. In March 2017, Darren Walker, the foundation's president, announced that it would commit $\$ 1$ billion to investments that "earn not only attractive financial returns but concrete social returns as well." 3

While the Acumen Fund and TPG are on different sides of the profitability spectrum, they are both committed to finding meaningful measurements of impact, specifically how much these companies contribute to solving a problem in addition to bringing in financial returns. In 2016, GIIN released its sixth Annual Impact Investor Survey. It reports that of the 158 respondents to the survey, 60 percent principally target riskadjusted, market-rate returns, while 25 percent target "below market-rate returns: closer to market rate" and 16 percent target "below market-rate returns: closer to capital preservation." 4

But Asia remains far from the center of the impact-investing sector. According to this survey, which includes most of the established fund managers in the field, only 5 percent of assets under management are in East and Southeast Asia and 8 percent in South Asia. Very little of that investment occurs in Asia, especially outside of India and Pakistan, a finding consistent with our research. While some of Asia shares in the growing interest and buzz around impact investing, it sees little such activity taking place on the ground. There are several reasons for this.

First is the availability of deals-or more accurately the lack thereof. Though there is desire on the part of social entrepreneurs and investors, there aren't as many social enterprises offering viable business plans. In fact, LGT Venture Philanthropy, one of the larger and most active funds, selected only 25 companies to pursue, of the 5000 considered. ${ }^{5}$ Six are now active in the LGT venture portfolio.

On the funding side, investors in Asia have not embraced impact investing to the extent that is taking place on other continents. In a recent South China Morning Post article, Stephen Tong, an investment consultant at global professional services firm Willis Towers Watson, said, "In Asia, many asset managers still see sustainable investment only as a risk-control tool to exclude certain sectors such as tobacco, rather than adopting a proactive and broader approach to build a portfolio with their own sustainable criteria." In the same article, Annie Chen, who might be the most informed impact investor in Asia, said that despite Hong Kong's role as a global financial center, the city lagged in the development of sustainable 
Table 8.1 Partial List of Impact Investing Funds in Asia

\begin{tabular}{|c|c|}
\hline China & $\begin{array}{l}\text { NPI (Non-profit Incubator), You Change (China Social Entrepreneur } \\
\text { Foundation) }\end{array}$ \\
\hline Hong & SOW Asia, Social Ventures Hong Kong, The Good Lab, Synergy Social \\
\hline Kong & Ventures \\
\hline India & Dasra, Start Up!, UnLtd India, Deshpande Fund, Villgro, Khosla Labs \\
\hline Indonesia & UnLtd Indonesia, Platform Usaha Sosial \\
\hline Japan & $\begin{array}{l}\text { Japan Venture Philanthropy Fund, Entrepreneurial Training for Innovative } \\
\text { Communities (ETIC) }\end{array}$ \\
\hline Malaysia & Social Enterprise Malaysia, My Harapan, Yayasan Hasanah \\
\hline Philippines & $\begin{array}{l}\text { ChooseSocial.PH, Philippine Social Enterprise Network, Institute for Social } \\
\text { Entrepreneurship in Asia, PRESENT Coalition }\end{array}$ \\
\hline Singapore & $\begin{array}{l}\text { Singapore Centre for Social Enterprise (raiSE), Social Innovation Park, } \\
\text { Social Enterprise Association }\end{array}$ \\
\hline South & Innov8social, Social Enterprise Leaders Forum (SELF), Work Together \\
\hline Korea & Foundation, SK Happiness Foundation \\
\hline Taiwan & Social Enterprise Insights, Social Enterprise Development Association \\
\hline Thailand & ChangeFusion, $\mathrm{C}$ asean \\
\hline
\end{tabular}

Source: Compiled by the Centre for Asian Philanthropy and Society (CAPS) 2016-2017

investment, lacking both demand and supply of such expertise compared to other global financial cities. ${ }^{7}$

Asia's lack of deals and interest in impact investing are changing, however. There is a great deal of enthusiasm around the subject. One indicator of this interest has been the increase in the number of conferences in Asia devoted to social enterprises and impact investing. These have included the International Symposium of Social Entrepreneurship (ISSE) 2016 (Singapore), Asian Venture Philanthropy Network (Hong Kong), Dasra Philanthropy Forum (India), Social Enterprise Summit (Hong Kong), and the Korea Impact Investing Network (South Korea), among others.

Another important trend in Asia is the increase in the number of local funds that provide financial and management assistance to start-up social enterprises. A partial list is shown in Table 8.1.

\section{Governments JoIn IN}

In addition to nonprofit initiatives, many governments in Asia are getting into the game. Hong Kong, Singapore, Thailand, South Korea, India, Malaysia, Taiwan, and Indonesia have each established funds to support the creation of social enterprises. The tricky part here is the definition of a 
social enterprise and the role the government can provide in supporting their creation and viability. There is great variability across countries.

The India Fund highlights the goal of supporting world-class enterprises that focus on the problems of the poor, a broad category. South Korea identifies such an organization as "a company that performs business activities while putting priority on the pursuit of social purposes." This definition stresses the primacy of the social bottom line. A social enterprise has to meet its financial obligations while also remaining committed to its social imperatives.

The challenge of this balancing act was made terribly clear by the case of SKS Financial, in the Indian state of Andhra Pradesh. Unable to pursue both goals simultaneously, SKS veered toward profit first, resulting in the state government closing it down after numerous suicides by overleveraged borrowers.

And it is not alone. Mohammed Yunus of Grameen Bank warned at the time of its IPO that by going public, there would be incredible market pressure to focus on financial returns. In response to such concerns, the Benefit Corporation or B Corp accreditation system was created in the United States and is now operating globally. Once accredited as a B Corporation, a company must maintain strict compliance with the profitability/purpose goals of the company. The first Indian company to become a certified B Corporation is eKutir, which listed in June, 2016. In China and Japan, three social enterprises are now listed. South Korea has the most, with ten social enterprises listed. It is fair to say this statistic shows that enthusiasm for social enterprises runs high in South Korea.

The most important component of government schemes is the availability of capital, especially in the start-up phase of the effort. Again, there is great variability. Singapore has put US\$6 million into two funds for social enterprises; one for grants and the other for impact investment. South Korea has put US\$28.3 million in its social enterprise support fund, and Thailand provides $\$ 1.2$ million in financial resources to social enterprises. For India, according to the Business Standard at the time of the announcement, the India Fund was seeded with Rs500 crore (about US\$77.5 million $)^{8}$ and expects to expand to Rs5000 crore once launched.

All of these funds also offer ancillary types of support such as help with networking, mentoring, incubation hubs, and registration assistance. The key question here is who is doing the mentoring? Generally, government bureaucrats and officials do not necessary know what makes a business plan viable. It is important that people with on-the-ground business 
experience come into the mix and apply their experience to the projects. In Hong Kong, the Social Enterprise Partnership Programme does so by serving as matchmaker between start-up social enterprises and private sector mentors who work with the teams as they develop their ideas and launch them as businesses.

\section{SOCIAL ENTERPRISES}

During our project, we included two types of social enterprises among our case studies - those that are businesses with a dual bottom line; and those that are hybrids, organizations that include profitable and not-for-profit components.

There were three social enterprises in our study that adhered to the South Korean definition; namely, businesses primarily promoting a social bottom line. Tree Planet is one such South Korean company and a registered B Corporation. Tree Planet leverages online entertainment to carry out conservation projects in two ways. It began by incorporating payment for tree planting into mobile gaming applications and web games. In these games, a player can choose to nurture a tree by paying a small fee, which is then used by the Tree Planet team to plant trees in South Korea and in ten other countries.

After working with the gaming app for some time, the Tree Planet managers realized that there was another way to encourage young people to support tree planting. They conceived of the idea of "star forests." Star forests capitalize on the extraordinary popularity throughout Asia of "K-Pop" or Korean music and drama stars. Fans pay for the planting of trees associated with their favorite star. In both the gaming and star forest initiatives, the government provides the land at no cost to Tree Planet. According to Tree Planet's website, it has planted 509,568 trees since its inception.

Landwasher, based in China, makes similar use of government partnership, but it did not begin that way. In 1999, Hao Wu left his job with a securities firm to address the need for sanitation in a country facing severe water shortages. He developed a waterless toilet with the intent of making it available throughout China but most especially in arid, rural areas. Landwasher was making some progress in building its business in rural China, but growth was somewhat slow due to the rather steep price tag of $\$ 5000$ to $\$ 8000$ for a 4 -unit toilet system. Then in 2008 it received a huge deal from the Beijing municipal government to supply all the toilets 
set up during the Beijing summer Olympics. According to Landwasher, it saved an estimated 1000 metric tons of water during the two weeks of the Olympic Games. " Since that time, Landwasher has been the "go-to" source of sanitation systems for large, government-organized events in China. Now that Landwasher has become a successful business, it is turning back to its original purpose of providing sanitation systems to poor, rural areas. It is working on developing a lower-priced model. According to founder $\mathrm{Wu}$, this is the most important challenge it faces today. ${ }^{10}$

Indonesia's Telapak, the third social enterprise included in our study, also began with modest roots. Its two founders, Ambrosius Ruwindrijarto and Silverius Oscar Unggul, started off as investigative journalists. They began working together on Telapak when they founded a radio station that informed local citizens about illegal logging taking place in their communities.

Since then, Telapak has branched into sustainable community logging, and it also advises companies on sustainability and CSR activities in Indonesia. It has become an association of multiple stakeholders committed to environmental conservation and protection. They work together to provide assistance to farmers, nonprofit groups working on environmental issues, businesses, and the government. Telapak has created a unique system that allows it to call upon relevant skill sets of those within the association to address a particular challenge, responding to numerous requests from companies and aid agencies in the past several years. It has proved a winning model, earning the organization and its leadership the prestigious Ramon Magsaysay Foundation Award, the Skoll Social Entrepreneur Award, and an Ashoka Fellowship.

All three of these case studies share several important elements. First, of course, they were founded by passionate and driven social entrepreneurs committed to a cleaner, more sustainable community and world. Second, they evolved in ways that used different strategies than originally planned, while maintaining the essential mission of the work. When harnessing market forces to succeed, a business must follow the market drivers. In the cases cited above, the path took the companies in new directions. Tree Planet realized that building star forests leveraged the almost cult status enjoyed by Korean K-Pop celebrities. Landwasher and Telapak became much more commercial. By selling sanitation systems to the Chinese government, Landwasher provided a much-needed public good, albeit not in the countryside where Hao Wu first made his decision to create an innovative social enterprise. Telapak must grapple with the balance of assisting 
local and multinational corporations as a consultant, while also criticizing them for activities causing environmental degradation.

Each of the organizations also tackles the challenge of assessment. Balancing profit and mission is always a challenge for social enterprises. Ideally, most can tackle this challenge when first designing their business plans. Once beyond that, however, the balancing act continues. All three of these social enterprises, like many others in the field, must also contend with the twin challenges of measurement versus mission.

As noted at the beginning of this chapter, businesses that try to "do good and do well" create a laudable but challenging goal for themselves. It does take discipline and commitment to maintain that delicate balance, a task that can be made easier when progress toward each goal can be measured. With that in mind, the Western world has put serious effort into finding measurement systems that capture the impact of an enterprise in addition to its sustainability. Rise, the TPG fund, has partnered with Bridgespan to create a "rigorous set of metrics with which to measure performance." ${ }^{11}$ In announcing the Ford Foundation's commitment to provide US\$1 billion to mission-related investments over the next ten years, the foundation stated that impact assessments have evolved sufficiently to warrant this type of investment. ${ }^{12}$

Asian organizations followed. The models from the West aren't ideal; they see mixed success, as it is difficult to develop frameworks on intangible benefits that can accrue. But some social enterprises' goods and services lend themselves more readily to impact assessment. Landwasher measures its success on how many toilets were set up and the tonnage of water that was saved by using its systems. Tree Planet measures how many trees and how many forests were planted as a result of its work. Educate Girls, a social enterprise offering fee-based educational opportunities for girls in Rajasthan, India, can measure the number of girls who received an education through its programs. All of these offer a product or service that had not been available previously. Their work, by definition, represents a net gain of services to the community.

Measurement becomes trickier when there are confounding variables. For example, while Telapak can say that during the time it has been involved in a community, illegal logging decreased, it cannot claim clear causality. Telapak itself does not feel comfortable taking this credit. "We don't want to be arrogant by telling people how much impact we have created to the community," said Khusnul Zaini, Telapak's president. ${ }^{13}$ 
In such cases, some organizations employ impact analyses that adhere to local situations. For example, to buttress arguments in favor of microfinance, the Grameen Foundation created the Progress out of Poverty Index (PPI). Aris Alip of the Center for Agriculture and Rural Development (CARD) says of PPI, "Now we have objective poverty data on our clients thanks to the Progress out of Poverty Index and Grameen Foundation's guidance on analysis; the results challenge us to do better."14 The challenge with the PPI is that it measures changes in poverty, but cannot show causality with the loans that the borrowers received.

Another similarity between the social enterprises in our study is the extraordinary degree of international acclaim and attention they have garnered. Telapak's awards are listed above. Tree Planet has received the Reddot Design Award, Google Innovation Award, and the iF design award, among others. Landwasher was picked by Fast Company as one of the 50 most innovative companies in 2013.

That isn't by accident. We wanted to study successful social delivery organizations (SDOs), and since international acclaim is one indicator of success, it's only natural that our case studies found firms garnering accolades. But there is more to it than that. Because there are few successful social enterprises in Asia, those that do succeed reap a great deal of attention and kudos. These high-performing organizations ride the wave of interest in impact investing amid a scarcity of alternatives, especially in East and Southeast Asia.

Lastly, all three social enterprises in our study benefit from a larger phenomenon of excitement about social enterprises, especially among young people. The Royal Bank of Scotland conducted a study that showed that people between the ages of 18-30 were more likely than the general population to want to start up a social enterprise (27 percent, compared to 20 percent), and more likely to consider supporting social causes that they are passionate about (70 percent, compared to 63 percent of the general population). ${ }^{15}$ Although no one tracks the actual ages of those running social enterprises in Asia, there is a great deal of anecdotal evidence favoring the young. Nini Daing, CEO of MyHarapan, a youth-focused organization in Malaysia, puts it best: "The challenges we face today require the naivety of our youth, our rebels with a cause, who are redefining success in their pursuit of a more meaningful life. The good news is that young people today are doing just this by rising up to take on these complex challenges to an unprecedented degree."16 


\section{Hybrid Projects}

There is one other type of social enterprise that is becoming more common in Asia: a hybrid organization. Here, that means a nonprofit organization that pursues social good while also supporting a business model that may work with its mandate, thereby creating sustainable income streams. In our case studies, there are three examples of this: Eden Social Welfare Foundation in Taiwan, CARD in the Philippines, and BAIF Development Research Foundation in India.

Eden Social Welfare Foundation was founded by Liu Hsia, herself disabled, to train other disabled people in Taiwan with skills that help them to be productive members of society. This helps them gain self-confidence from their ability to earn an income and contribute to their families' wellbeing. In the past 30 years, Eden has grown from a staff of two, including Liu Hsia, to an organization that employs 2800 full-time staff across 85 offices in 21 counties and cities. Its budget/funding is now US\$49.5 million per annum. ${ }^{17}$

The growth has been extraordinary. Originally focusing on job skills, its services have expanded to include psychological counseling, sheltered workshops, employment referral, talent and skill training, cultural and recreational activities, and gospel delivery. As Eden grew and trained more and more people, they outstripped the jobs available to them, so it began to create its own businesses to employ those it had trained. It started with a small factory employing six people making good quality local handicrafts. Then it expanded into restaurants and bakeries, and then computer training and coding. Now, alongside skill and job training, Eden works with its clients to help with interpersonal and communication training, counseling, and career advice. The businesses that Eden runs are an integral part of its core mission to help disabled people, but they also provide a very real benefit to Eden itself. Last year, 14.4 percent of the total budget came from the businesses it has created. Eden has truly created a winwin situation by building social enterprises alongside its nonprofit programs.

CARD in the Philippines is another great success story. In 1986, Aris Alip and 14 other social entrepreneurs set up a microfinance organization with the goal of providing credit to rural poor involved primarily with agribusiness efforts. Unfortunately, the early results were not promising. Many borrowers did not pay back the loans. So Alip and his colleagues searched for alternative models. One such model was Grameen Bank in 
Bangladesh. CARD adapted for the Philippines the women-focused group-lending model that Grameen had pioneered. It included the notion that CARD's customers should also become part of the management of the organization. This way, the reasoning went, CARD would always be customer-focused.

The changes that it put in place made all the difference. CARD now has 30 affiliated organizations and businesses. It owns banks to cater to those customers who have moved beyond micro-credit and need more capital. It offers insurance and education. It has training affiliates for its customers as well as for its own employees. It offers customers and employees low-cost medications. CARD has become a holding company, with some of its portfolio organizations maintaining their nonprofit status while others are social enterprises. They work together, complementing each other and providing a range of services to their customers, many of whom are involved with some aspect of the management of the organization. Through experimentation, a willingness to take risks, staying very close to the needs of rural women, and through the novel combination of nonprofit and social enterprise models, CARD has grown into one of the Philippines' most important SDOs.

A third example of a hybrid organization in our study is BAIF, which works with farmers in India to help them use technology and advanced agribusiness methods to improve their productivity and increase their incomes. Established in 1967, it has helped 5,892,045 families with improved animal husbandry techniques and 201,144 rural families in planting "wadi" orchards, allowing farmers to rear fruit trees, flowers, and vegetables more efficiently.

Inspired by Mahatma Gandhi's call for Indian self-sufficiency, BAIF's founder Manibhai Desai committed himself to improving rural livelihoods. His first important breakthrough was the realization that the milk yields of native Indian Gir cattle went up dramatically when the cows were interbred with Dutch Holstein-Friesian and British Jersey cows. He developed a system for widespread application of artificial insemination that is now being used in 16 Indian states. From the very beginning, BAIF both worked across and brought together its mission-driven ethos with government support, business acumen, and financial reward into a package that creates win-win-win impact. In its multifaceted agribusiness programs, BAIF does seek government and aid agency support, but it also provides numerous jobs to BAIF agricultural technicians and charges farmers for their services. These charges add a crucial income stream to BAIF's bottom line and align commitment between all stakeholders. 
In the cases of BAIF, CARD, and Eden, the profitable and the nonprofit, the mission and the enterprise are mutually reinforcing. The business imperative was created as a means to accomplish the humanitarian goals of the organization. In all three cases, the business initiatives grew organically from the needs and opportunities created by the organizations while following their missions. The benefit of this model is that the business angle did not come first, only to be later structured to support the mission. There is less concern with the delicate balance described earlier for social enterprises created as businesses. Of course, not all nonprofit organizations and agendas lend themselves to the creation of social enterprises like BAIF, CARD, and Eden have done, but it is a compelling model and one worth emulating when the circumstances are right.

\section{CONCLUSION}

Enthusiasm for applying business tools and entrepreneurial rigor to social challenges is high, and in many respects getting higher. This trend brings much benefit, along with at least one potential pitfall. On the positive side, there is great energy, talent, and excitement in this space. Forbes magazine puts out an annual "Social Entrepreneurs under 30" issue.

If there is any downside to bringing business acumen to the nonprofit world, it may be in excessive expectations. The tag line to that Forbes article is "Leveraging business tools to save the world." In the text, Forbes says that these young social entrepreneurs are solving the world's toughest problems. This type of language, while extolling the virtues of these endeavors and helping to expand the buzz and excitement around this type of work, also showcases one of the misnomers of the field. Do social enterprises really solve some of the world's greatest challenges?

Taking a look at the three cases in our study, it is difficult to make the argument that any of these social enterprises will solve problems at their root. While Tree Planet does in fact plant trees, it is not solving the widespread problem of deforestation. While Landwasher provides toilets, it is not addressing the need for sanitation systems in arid communities; and while Telapak can advise businesses on how to source commodities in the most sustainable ways possible, it cannot change the way globalization and resource extraction are taking place throughout the world today. Social enterprises do make a positive difference, but we need to be clear that they cannot, in and of themselves, "solve" the biggest challenges. Many of these problems are complex and multifaceted, requiring complex and 
multifaceted solutions. To really solve these challenges at their most fundamental levels, we need to bring together business and government and civil society in an unprecedented manner.

In Asia, it is critical for donors and policymakers to understand that while promoting social entrepreneurship is great, these efforts cannot be in lieu of other interventions. Rather, they shine as part of a set of initiatives that can work together to address seemingly intractable problems.

\section{Notes}

1. The New York Times. Dealbook. December 20, 2016. https://www. nytimes.com/2016/12/19/business/dealbook/a-new-fund-seeks-bothfinancial-and-social-returns.html?_r=0. Accessed December 20, 2016.

2. The Rise Fund corporate website. http://therisefund.com. Accessed February 20, 2017.

3. Ford Foundation News Release. "Ford Foundation Commits \$1 Billion from Endowment to Mission Related Investments." April 5, 2017. https://www.fordfoundation.org/the-latest/news/ford-foundationcommits-1-billion-from-endowment-to-mission-related-investments/. Accessed February 20, 2017.

4. Mudaliar, Abhilash, Hannah Schiff and Rachel Bass. "Annual Investor Survey 2016." Global Impact Investing Network, May 2016, p. 12.

5. LGT Venture Philanthropy. "Portfolio Overview." http://www.lgtvp. com/lgt/files/28/28d60948-3cdc-4dd2-85d7-337234845b2f.pdf. Accessed December 10, 2016.

6. South China Morning Post. "Wealth Can Be Green." January 9, 2017.

7. Ibid.

8. Approximately US\$77.5 million in May, 2017 exchange rates.

9. Zhang, Tao, Tim Yin, and Christine Yip. "Landwasher, Guardian of the Blue Earth." CAPS Case Study, p. 4.

10. Ibid., p. 7.

11. Sorkin, Andrew Ross. "A New Fund Seeks Both Financial and Social Returns." The New York Times, December 20, 2016, p. Bl.

12. Ford Foundation News Release. "Ford Foundation Commits \$1 Billion from Endowment to Mission Related Investments." April 5, 2017. https://www.fordfoundation.org/the-latest/news/ford-foundationcommits-1-billion-from-endowment-to-mission-related-investments/. Accessed April 20, 2017.

13. Radyati, Maria. "Telapak: Seeking Natural Resource Justice for Communities." CAPS Case Study, p. 10.

14. Progress out of Poverty Index. http://www.progressoutofpoverty.org/ testimonials. Accessed April 4, 2017. 
15. RBS Enterprise Tracker (in collaboration with Unltd), 2nd quarter, 2013, London, p. 4.

16. In conversation, April 19, 2017.

17. Huang, Ping-Der and Sylph Yang. "Sustainability Through Innovation." CAPS Case Study, p. 2.

Open Access This chapter is licensed under the terms of the Creative Commons Attribution 4.0 International License (http://creativecommons.org/licenses/ by $/ 4.0 /$ ), which permits use, sharing, adaptation, distribution, and reproduction in any medium or format, as long as you give appropriate credit to the original author(s) and the source, provide a link to the Creative Commons license and indicate if changes were made.

The images or other third party material in this chapter are included in the chapter's Creative Commons license, unless indicated otherwise in a credit line to the material. If material is not included in the chapter's Creative Commons license and your intended use is not permitted by statutory regulation or exceeds the permitted use, you will need to obtain permission directly from the copyright holder.

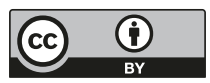

